\title{
Preparation of Heat-Sensitivity Proteins from Walnut Meal by Sweep Frequency Ultrasound-Assisted Alkali Extraction
}

\author{
Wenjuan Qu $\mathbb{D}^{1},{ }^{1}$ Wei Fan, ${ }^{2}$ Yiting Feng, ${ }^{2}$ Yunliang $\mathrm{Li}^{2}{ }^{2}$ Haile Ma $\mathbb{D}^{1},{ }^{1}$ and Zhongli Pan ${ }^{3}$ \\ ${ }^{1}$ Institute of Food Physical Processing, Jiangsu University, 301 Xuefu Road, Zhenjiang, Jiangsu 212013, China \\ ${ }^{2}$ School of Food and Biological Engineering, Jiangsu University, 301 Xuefu Road, Zhenjiang, Jiangsu 212013, China \\ ${ }^{3}$ Department of Biological and Agricultural Engineering, University of California,Davis, One Shield Avenue, Davis, \\ CA 95616, USA
}

Correspondence should be addressed to Wenjuan Qu; wqu@ujs.edu.cn

Received 27 May 2021; Accepted 25 June 2021; Published 9 July 2021

Academic Editor: Shengbao Cai

Copyright (C) 2021 Wenjuan Qu et al. This is an open access article distributed under the Creative Commons Attribution License, which permits unrestricted use, distribution, and reproduction in any medium, provided the original work is properly cited.

\begin{abstract}
Sweep frequency ultrasound- (SFU-) assisted alkali extraction was conducted to increase the yield and content of heat-sensitive protein of walnut meal under a relatively mild condition. The physicochemical and structural characteristics of the proteins obtained by SFU-assisted alkali extraction and the conventional alkali extraction were compared. It was found that the optimal parameters for the SFU-assisted extraction were the solid-liquid ratio of $1: 12, \mathrm{pH}$ value of 9 , initial temperature of $25^{\circ} \mathrm{C}$, ultrasonic frequency of $28 \mathrm{kHz}$, sweep frequency amplitude of $1.5 \mathrm{kHz}$, sweep frequency cycle of $100 \mathrm{~ms}$, duty ratio of $77 \%$, and ultrasonic time of $90 \mathrm{~min}$. Under this condition, a vast improvement in the walnut protein yield $(34.9 \%)$ and the walnut protein content (9.8\%) was observed. Such improvement was due to the structural changes of the sonicated protein; e.g., SFU decreased the intermolecular/intramolecular hydrogen bond force of proteins and, therefore, caused more order secondary structures and more loosen microstructures. This helped to improve the thermoplastic and solubility of the heat-sensitivity protein. Thus, SFU treatment could be an effective auxiliary technology in the alkali extraction of heat-sensitivity walnut protein. It might also be a promising technology for the extraction of heat-sensitivity protein from other agricultural by-products.
\end{abstract}

\section{Introduction}

The world production of walnut is large, increasing year by year. As a healthy foodstuff, walnuts have gradually aroused extensive attention. It was reported that regular consumption of walnuts could reduce the risk of coronary heart disease [1]. Meanwhile, walnuts can be utilized as ingredients for many foodstuffs such as bakery products to enhance the nutrition value and the sensory properties of the final product [2]. There are a great variety of nutrition ingredients in walnuts including protein, magnesium, copper, folic acid, potassium, fiber, and vitamin E [3].

The main by-product of the walnut oil extraction process is the defatted walnut meal. Most of the walnut meal is used as animal feed, fish meal, fertilizer, or directly discarded, which could result in a waste of resources $[4,5]$. It was reported that walnut meal contains $52.5 \%$ protein $[6,7]$.
With the development of textured protein (such as extruded artificial meat), the demand for low-temperature extracted protein with good thermoplastic, solubility, and foaming properties has been increased. Thus, a walnut protein with a low degree of denaturation (good thermoplasticity) was of great value. However, the protein ingredient in a walnut meal has not been well used in food processing because of the limited information on its structural and functional properties [8]. The proteins' structural and functional properties correlate to their preparation method. There are many studies on the extraction and structure of plant proteins $[9,10]$, but the studies of walnut protein mainly focused on the long-time and high-concentration alkalisoluble extraction $[11,12]$. Nevertheless, the functional investigation of protein by this method showed some loss of nutritional value, such as the degradation of protein, the potential toxicity, and the formation of lysinoalanine, due to 
extreme alkaline conditions. Thus, there is a need to explore a green technology to replace alkali extraction.

Ultrasound-assisted extraction has been widely applied in food, chemical, and biological processes [13, 14]. Essentially, the ultrasonic treatment can further improve the alkali extraction process of protein by reducing the amount of alkali or increasing the yield [15]. Meanwhile, the heatsensitive compound can be extracted with minimal damage and higher extraction yield through this extraction method [16]. Therefore, the combination of ultrasound and alkaline in the heat-sensitivity protein extraction process (extraction temperature is usually under $60^{\circ} \mathrm{C}$ ) is feasible.

Compared to the conventional ultrasound with a fixed frequency, sweep frequency sonication could generate more cavitation, which could improve the protein gelling properties and protein enzymolysis efficiency [17, 18]. From the acoustic point of view, compared with the fixed frequency ultrasound, sweep frequency ultrasound can produce a more conducive sound field to improve the cavitation effect [19]. However, there is no research report on the extraction of walnut protein by sweep frequency ultrasound (SFU). Therefore, in this research, SFUassisted extraction was introduced to walnut protein extraction in order to reduce the amount of alkali and improve the yield and content of protein under relatively mild conditions. Correspondingly, we studied the effects of SFU parameters (i.e., ultrasonic frequency, sweep frequency amplitude, sweep frequency cycle, duty ratio, solid-liquid ratio, $\mathrm{pH}$, initial temperature, and ultrasonic time) on the extraction efficiency of walnut protein. Moreover, the changes in protein structure and thermal stability caused by SFU treatment were determined compared to the conventional alkali extraction. The mechanism of SFU-assisted extraction was investigated. This research provides a practical strategy and solid foundation for ultrasonic extraction of heat-sensitivity proteins from agricultural by-products.

\section{Materials and Methods}

2.1. Materials and Reagents. Walnut meal defatted under a low temperature $\left(<60^{\circ} \mathrm{C}\right)$ was obtained from Xi'an Bodaver Biotechnology Co. Ltd (China). Sodium hydroxide $(\mathrm{NaOH})$, hydrochloric acid ( $\mathrm{HCl})$, bovine serum albumin (BSA), Folin-phenol reagent, potassium bromide $(\mathrm{KBr})$, and other chemical reagents were purchased from the Sinopharm Chemical Reagent Co. Ltd (China). All reagents used in the experiments were of analytical grade.

\subsection{SFU-Assisted Alkali Extraction Process of Walnut Protein.} The walnut meal was dissolved to a fixed solid-liquid ratio, and the $\mathrm{pH}$ was adjusted to a fixed initial $\mathrm{pH}$ by adding $4.0 \mathrm{~mol} / \mathrm{L} \mathrm{NaOH}$. Then, the sample solution was poured into an ultrasonic bag, sealed, and submerged into the ultrasonic reactor of the SFU equipment with $9 \mathrm{~L}$ added water. The SFU equipment (Figure 1) was manufactured by Jiangsu University with upper and lower ultrasonic transducers (total ultrasonic power of $1200 \mathrm{~W}$ ). The sample solution in the ultrasonic bag was treated under the ultrasonic power intensity of $133.3 \mathrm{~W} / \mathrm{L}$ at a fixed initial temperature for a fixed ultrasonic time. After SFU extraction, the solution was centrifuged at $5,000 \mathrm{r} / \mathrm{min}$ for $15 \mathrm{~min}$ by a centrifuge (Feige licensing DL-5-B, Shanghai Anting Scientific Instrument Factory, China), and then, the solution was adjusted to $\mathrm{pH}$ 4.5 by using $1.0 \mathrm{~mol} / \mathrm{L} \mathrm{HCl}$. After standing for $20 \mathrm{~min}$, the solution was centrifuged again and washed until it was neutralized by distilled water. The wet protein precipitate was collected and freeze-dried by using a freeze dryer (FD-8, Beijing Boyikang Laboratory Instrument Co. Ltd, China).

\subsection{Optimization of SFU-Assisted Alkali Extraction} Parameters. The frequency of SFU treatment was fixed at the center frequency $(f \mathrm{kHz})$ with a sweep frequency amplitude $(\delta \mathrm{kHz})$ of $f \pm \delta \mathrm{kHz}$. So, the upper limit of frequency was $f+\delta \mathrm{kHz}$ and the lower limit was $f-\delta \mathrm{kHz}$. In this experiment, the ultrasonic working mode was optimized. The working mode parameters include the ultrasonic frequency $(f=28,33,40,68 \mathrm{kHz})$, sweep frequency amplitude $(\delta=0.0,0.5,1.0,1.5,2.0 \mathrm{kHz})$, sweep frequency cycle $(20$, $100,300,600$, and $1000 \mathrm{~ms}$ ) referring to the time of one periodic fluctuation from $f-\delta \mathrm{kHz}$ to $f+\delta \mathrm{kHz}$, and duty ratio $(33 \%, 50 \%, 77 \%$, and $90 \%)$ referring to the percentage of the ultrasonic running time over the total ultrasonic time. The other extraction parameters including solid-liquid ratio $(1: 9,1: 12,1: 15,1: 18,1: 21$, w/v), initial $\mathrm{pH}$ value $(7,8,9$, $10,11)$, initial temperature $\left(15,25,35,45\right.$, and $\left.55^{\circ} \mathrm{C}\right)$, and ultrasonic time $(5,10,18,30,60,90,120$, and $150 \mathrm{~min})$ were also considered and optimized. The content and yield of walnut protein were set as indices for the optimization of these parameters. Meanwhile, the conventional alkali extraction without ultrasound was conducted under the same conditions as optimal SFU extraction and was selected as the control.

\subsection{Determination of Protein Yield and Protein Content.} The protein powder was accurately weighed $5 \mathrm{~g}\left(m_{1}\right)$, mixed with distilled water until completely dissolved, and then the protein solution was fixed to $500 \mathrm{~mL}$. Then, the protein solution was diluted 20 times, and the protein concentration was determined by the Folin-phenol method [20]. The protein concentration $(c, \mathrm{mg} / \mathrm{mL})$ was calculated by the BSA standard equation $\left(c=2.094 x+0.60, R^{2}=0.997\right)$ based on the absorbance $(x)$. The content and yield of protein were, respectively, calculated using the following equations:

$$
\begin{aligned}
& \text { protein content }(\%)=\frac{c \times v \times n}{m_{1} \times 10}, \\
& \text { protein yield }(\%)=\frac{c \times v \times n \times m}{m_{1} \times M \times 10},
\end{aligned}
$$

where $n$ is the dilution time (20); $v$ is the volume of protein solution $(500 \mathrm{~mL}) ; m_{1}$ is the weight of weighted protein powder $(5 \mathrm{~g}) ; m$ is the weight of collected all protein powder $(\mathrm{g}) ; M$ is the weight of input walnut meal $(\mathrm{g})$. 


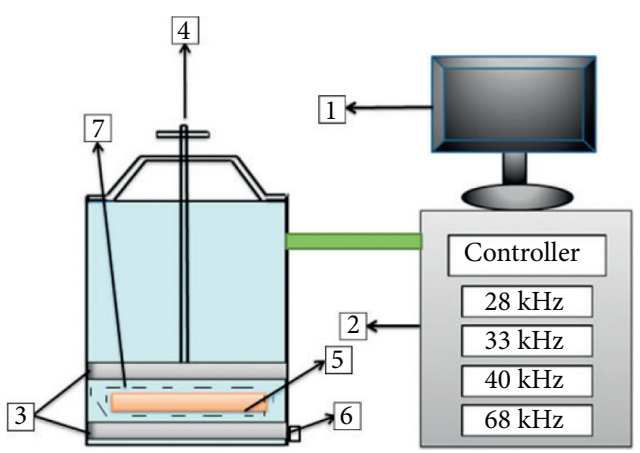

FIGURE 1: Sweep frequency ultrasound (SFU) equipment schematic diagram (1: computer control system; 2: ultrasonic controller; 3 : upper and lower two ultrasonic transducers; 4: height adjusting screw; 5: sample solution in the ultrasonic bag; 6 : water outlet; 7: added water).

\subsection{Structural and Functional Analysis}

2.5.1. Measurement of Fourier Transform-Infrared (FT-IR). The FT-IR spectra of the protein samples extracted with and without ultrasound were scanned by using a Fourier infrared spectrometer (Nicolet is50, Thermo Electron Corporation, America). According to the reported method [21], the ratio of sample to $\mathrm{KBr}$ was set at $1: 100(\mathrm{w} / \mathrm{w})$. At room temperature $\left(25 \pm 1^{\circ} \mathrm{C}\right)$, the scanning wavenumber spectrum range was $4000 \sim 400 \mathrm{~cm}^{-1}$, and the resolution was $4 \mathrm{~cm}^{-1}$.

2.5.2. Measurement of Fluorescence. The fluorescence spectra of the protein samples extracted with and without ultrasound were scanned by using a fluorescence spectrophotometer (Cary Eclipse, Agilent Technologies Co. Ltd, China). Fluorescence was performed according to the method [21], and the method was slightly adjusted. The sample concentration of $0.05 \mathrm{mg} / \mathrm{mL}$ was used for determination. The emission spectrum detection was conducted at the excitation wavelength of $340 \mathrm{~nm}$ and the emission wavelength of 400 500 nm with a scanning speed of $600 \mathrm{~nm} /$ min and a slit width of $5 \mathrm{~nm}$. The conditions of excitation spectrum scanning were as follows: emission wavelength was $430 \mathrm{~nm}$, the excitation wavelength was $300 \sim 400 \mathrm{~nm}$, and other conditions were the same as the conditions of emission spectrum scanning.

2.5.3. Measurement of Circular Dichroism (CD). The protein samples extracted with and without ultrasound at a concentration of $1.0 \mathrm{mg} / \mathrm{mL}$ were desalted by ultrafiltration $(3 \mathrm{kDa})$ and then rehydrated to the original concentration. The solution was scanned by using a circular dichroism (CD) spectrometer (J-815, JASCO Corporation, Japan) in an $\mathrm{N}_{2}$ charged environment. The parameters of $\mathrm{CD}$ were obtained based on the method reported by Hou et al. [22]. The scanning speed was $50 \mathrm{~nm} / \mathrm{min}$, the resolution was $0.1 \mathrm{~nm}$, and the response time was $1 \mathrm{~s}$. The generated data was used to calculate the content of the secondary structure by using analytical CDPro software (IBM Corporation, NY, USA).
2.5.4. Measurement of Scanning Electron Microscope (SEM). The microstructures of the protein samples extracted with and without ultrasound were studied by using a SEM device (S-3400N, HITACHI Corporation, Japan). The sample was glued on the sample table with the double-sided conductive adhesive, and gold was sprayed on the surface of the sample by an ion sputtering apparatus. The sample was placed under SEM $(15 \mathrm{kV})$ to observe the microstructure.

2.5.5. Measurement of Thermal Stability. The thermal stability properties of the protein samples extracted with and without ultrasound were studied by using a synchronous thermal analyzer (STA449F3, NETZSCH Corporation, Germany). According to the reported method [23], the sample was heated from $25^{\circ} \mathrm{C}$ to $800^{\circ} \mathrm{C}$. The heating rate was $10^{\circ} \mathrm{C} / \mathrm{min}$, and the nitrogen flow rate in the sample chamber was $70 \mathrm{~mL} / \mathrm{min}$.

2.6. Statistical Analysis. Each measurement was repeated three times. The data presented in this study was mean\pm standard deviation. Results were statistically analyzed to identify differences by using one-way ANOVA and Duncan's test under the significance level of $p<0.05$ using SPSS 19.0 software (IBM Corporation, NY, USA).

\section{Results and Discussion}

\subsection{Optimization of SFU-Assisted Extraction Parameters}

3.1.1. Ultrasonic Frequency. Frequency is an important factor in determining the ultrasonic field characteristics and also a key factor influencing cavitation [24]. The effects of ultrasonic frequency $(28,33,40$, and $68 \mathrm{kHz})$ on the yield and content of walnut protein were studied, and the data is shown in Figure 2(a). The results revealed that the protein yield and protein content fluctuated significantly with the change of ultrasonic frequencies $(p<0.05)$. The highest protein yield and protein content were observed at $28 \mathrm{kHz}$, and the lowest values were found at $33 \mathrm{kHz}$. This indicated that $28 \mathrm{kHz}$ ultrasonic frequency was more conducive to protein extraction. The lowest value at $33 \mathrm{kHz}$ was because of the resonance effect with the protein, which damaged the protein structure. Therefore, the content and yield of protein at $33 \mathrm{kHz}$ were decreased significantly $(p<0.05)$. Raviyan et al. [25] also reported that when the conducted ultrasonic frequency $f a$ was close to the resonance frequency $f r$ of the system, the ultrasonochemical damage effect of the system reached the maximum. Similarly, Ren et al. [26] reported that $33 \mathrm{kHz}$ ultrasound had the strongest protein damage effect. Apart from the resonant frequency of $33 \mathrm{kHz}$, the ultrasonic effect at other frequencies $(28,40$, and $68 \mathrm{kHz})$ had a relatively high solubility promoting effect, showing a high protein yield. With the increase of ultrasonic frequency, the effect of protein solubilization became weaken. This may be because a higher frequency of ultrasound is easy to cause protein aggregation, which is not conducive to dissolution. Yang et al. [20] also reported that with the increase of ultrasonic frequency, the damaging effect was more strong. 
Similarly, Wang et al. [19] reported that the degradation rate of phenolic acids was increased with the increase of ultrasonic frequency. These results are consistent with our findings where only an appropriate ultrasonic frequency away from the resonance frequency was beneficial to maintain a high dissolution of protein. Thus, the frequency selection of ultrasound treatment was essential for the extraction of protein. Overall, by full consideration of the protein extraction yield, the protein content, and the energy consumption of the ultrasound, it was appropriate to select $28 \mathrm{kHz}$ in this study and applied to the following optimization.

3.1.2. Sweep Frequency Amplitude. The effects of amplitude $(0.0,0.5,1.0,1.5$, and $2.0 \mathrm{kHz})$ on the yield and content of walnut protein were studied and the data is shown in Figure 2(b). As the sweep frequency amplitude changed, the protein yield significantly increased from $0.5 \mathrm{kHz}$ to $1.5 \mathrm{kHz}$ and then significantly declined from $1.5 \mathrm{kHz}$ to $2.0 \mathrm{kHz}$ $(p<0.05)$. The protein content showed the same tendency as the protein yield. At the sweep frequency amplitude of $1.5 \mathrm{kHz}$, both protein yield $(14.7 \%)$ and protein content $(34.7 \%)$ reached the highest. It was because, with the increasing sweep frequency amplitude, the ultrasonic cavitation effect gradually increased, and hence, the protein dissolution was accelerated. Wang et al. [19] also reported that sweep frequency ultrasound amplitude indeed affected the strength of cavitation. Therefore, the yield and content of protein were significantly increased by increasing sweep frequency amplitude. However, with the increased sweep frequency amplitude, the number of cavitation bubbles also increased. The destructive effect of ultrasound was more apparent due to the gradual approach of the ultrasonic frequency to the resonant frequency [27]. Thus, the yield and content of protein were decreased by excessive sweep frequency amplitude. Therefore, ultrasound with a moderate sweep frequency amplitude was conducive to accelerate protein dissolution. Furthermore, it was found that the yield and content of protein extracted by the sweep frequency ultrasound were significantly higher than those by the fixed frequency ultrasound (amplitude was $0.0 \mathrm{kHz}$ ). It was indicated that sweep frequency ultrasound was more advantageous to improving the effect of protein solubilization than fixed frequency ultrasound, which might be because the ultrasonic cavitation of the sweep frequency ultrasound was stronger than that produced by fixed frequency ultrasound [25]. Similarly, Ren et al. [26] reported that the effect of ultrasonic cavitation of the sweeping model was better than that of the fixed model. Wang et al. [19] also reported that the cavitation of FSFP (flat sweep frequency and pulsed) ultrasound was stronger than that of the fixed frequency ultrasound. Based on the above conclusions, the optimized sweep frequency amplitude of $1.5 \mathrm{kHz}$ was selected and applied to the following optimization.

3.1.3. Sweep Frequency Cycle. The effects of the sweep frequency cycle $(20,100,300,600$, and $1000 \mathrm{~ms})$ on the yield and content of walnut protein were studied. As can be seen in Figure 2(c), the sweep frequency cycle of $100 \mathrm{~ms}$ had a significantly greater impact on the yield and content of protein than those of the other four sweep frequency cycles $(20,300,600$, and $1000 \mathrm{~ms})(p<0.05)$. This was ascribed to the strongest cavitation effect from the sweep frequency cycle of $100 \mathrm{~ms}$. A shorter sweep cycle $(<100 \mathrm{~ms})$ means a faster change of sweep frequency, which produces a bigger vibration, weakens the cavitation effect, and therefore shows a lower yield and content of protein. With the increase of sweep frequency cycle $(>100 \mathrm{~ms})$, the protein yield and protein content decreased significantly. The lower yield and content of protein at $300 \sim 1000 \mathrm{~ms}$ might be due to the increased proportion of the resonance area caused by a slower frequency change and enhanced destroying effect of ultrasound. Wang et al. [19] also reported that either too short or too high sweep frequency cycle of ultrasound treatment could result in a large degradation rate of protein. Therefore, a moderate sweep frequency cycle was beneficial to maintain the high yield and content of protein. In this study, $100 \mathrm{~ms}$ was selected as the optimized sweep frequency cycle for the following optimization.

3.1.4. Duty Ratio. The effects of duty ratio (33\%, $50 \%, 77 \%$, and $90 \%$ ) on the yield and content of walnut protein were studied, and the data is shown in Figure 2(d). With the increase in the duty ratio, the yield and content of protein increased significantly, reached the maximum at the duty ratio of $77 \%$, and then significantly decreased $(p<0.05)$. The higher ultrasonic duty ratio represents the stronger cavitation. As the increasing ultrasonic duty ratio, stronger cavitation accelerated the protein dissolution. Lin et al. [28] also reported that the threshold of ultrasound cavitation was positively correlated with pulse duration. In addition, the mechanical shear of ultrasonic treatment at the high duty cycle could promote the disaggregation or dispersion of protein in the aqueous solution and lead to the increased extraction yield of protein [27]. However, a large number of cavitation bubbles generated by too high duty ratio also increased the scattering and refraction of ultrasonic wave, which could lead to the decrease of ultrasonic effect [19]; thus, a reduction was observed in the yield and content of protein at the duty ratio beyond $77 \%$. The observations indicated that duty ratio significantly affected the extraction of protein. Based on the present results, either too low or too high ultrasonic duty ratio was not beneficial to maintain the high extraction performance. Therefore, a moderate ultrasonic duty ratio could be beneficial to maintain the high yield and content of protein. In this study, $77 \%$ was selected as the optimized duty ratio and applied to the following optimization.

3.1.5. Solid-Liquid Ratio. The effects of solid-liquid ratio (1: $9,1: 12,1: 15,1: 18$, and $1: 21)$ on the yield and content of walnut protein were studied, and the data is shown in Figure 3(a). It showed that the yield of walnut protein increased slightly from $1: 21$ to $1: 12$ and then significantly decreased from $1: 12$ to $1: 9(p<0.05)$. In the experimental range, the yield $(11.1 \%)$ of walnut protein reached the 


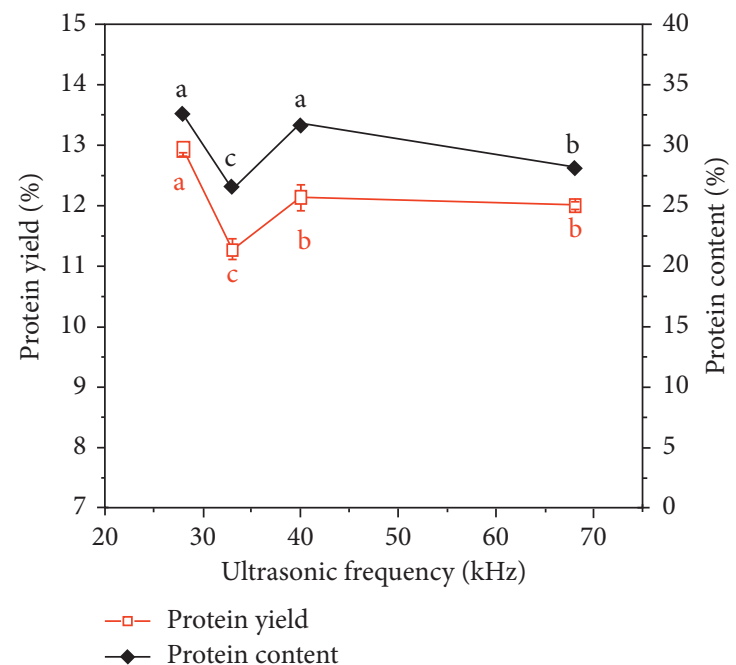

(a)

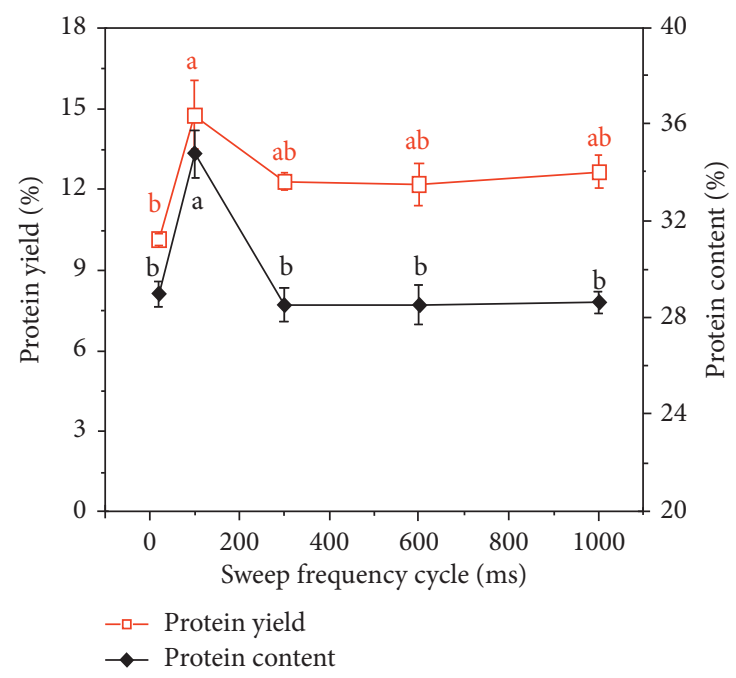

(c)

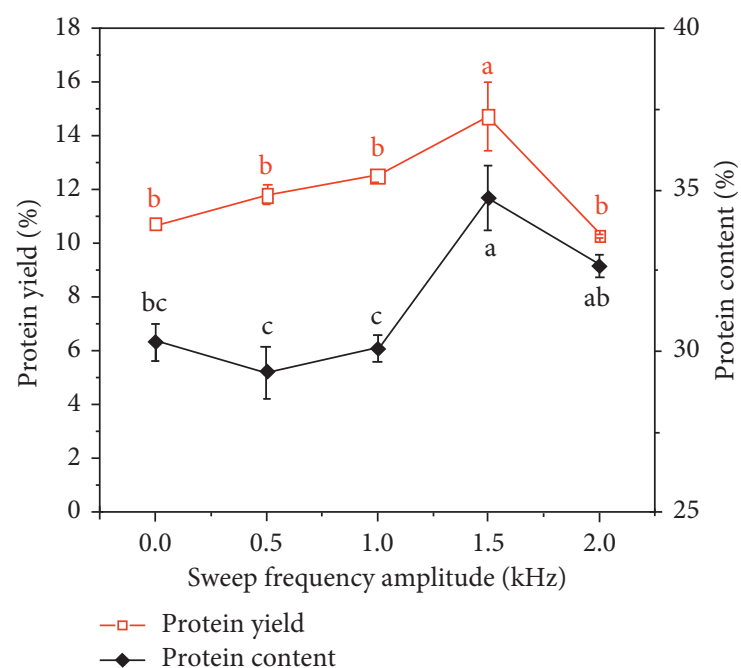

(b)

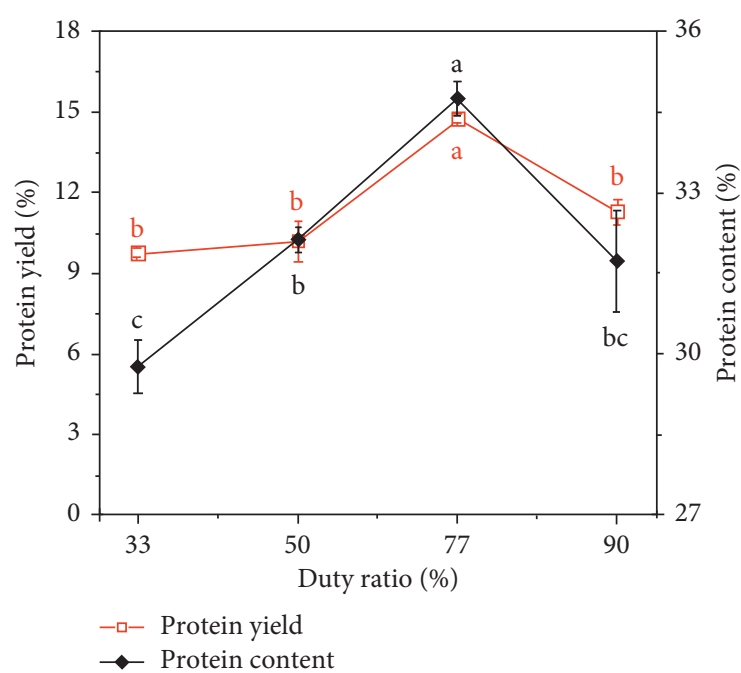

(d)

Figure 2: Effects of ultrasonic frequency (a), sweep frequency amplitude (b), sweep frequency cycle (c), and duty ratio (d) on the yield and content of walnut protein. The different superscript letters of data under the same line indicate that they are significantly different $(p<0.05)$.

highest at the solid-liquid ratio of $1: 12$. The lower yield at the solid-liquid ratio of $1: 9$ was due to a lower protein proportion in the amount of walnut meal added [29]. With the amount of walnut meal added to increase in a fixed volume of solution (from $1: 21$ to $1: 12$ ), the protein solubility and the protein yield gradually increased. When the soluble protein reached saturation in a fixed volume of solution, the protein concentration reached the highest at the solid-liquid ratio of $1: 12$ [30]. When the amount of walnut meal added continued to rise (from $1: 12$ to $1: 9$ ), the amount of soluble protein did not change, resulting in a lower proportion of protein in the amount of walnut meal added and so a decreasing protein yield. The trend of solid-liquid ratio on the protein content was the same as that on the protein yield. The highest protein content $(32.6 \%)$ was obtained at the solid-liquid ratio of $1: 12$. The content of walnut protein in the extract increased first and then significantly decreased from $1: 12$ to $1: 9(p<0.05)$. $\mathrm{Xu}$ et al. [31] also found that the content of soluble leaf protein increased as the ratio of solid to liquid increased, and when the ratio continued to rise, the content of soluble leaf protein decreased. Based on the present results, it was appropriate to select the solid-liquid ratio of $1: 12$ for the following optimization.

3.1.6. $p H$ Value. The effects of $\mathrm{pH}$ value $(7,8,9,10$, and 11$)$ on the yield and content of walnut protein were studied, and the data is shown in Figure 3(b). It showed that the protein yield significantly increased with the increasing $\mathrm{pH}$ value $(p<0.05)$. The protein yield increased rapidly within the $\mathrm{pH}$ range of 7 9, and then, the growth rate became slow after $\mathrm{pH}$ 9. It was obvious that the alkaline environment had a significantly positive solubilization effect on the walnut protein. Stronger alkalinity means better solubility and a higher protein yield. This was because the high concentration of alkaline can result in the breakdown of the hydrogen bond of 


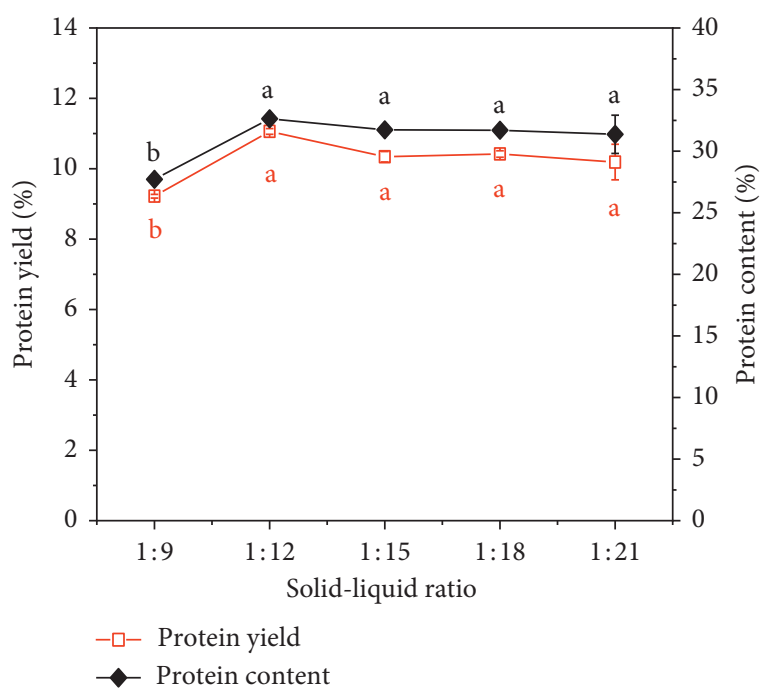

(a)

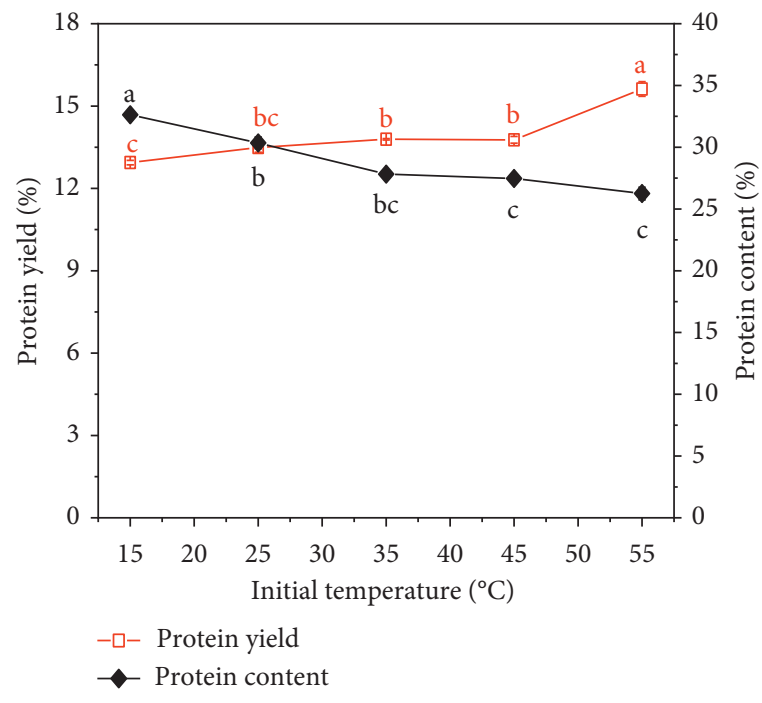

(c)

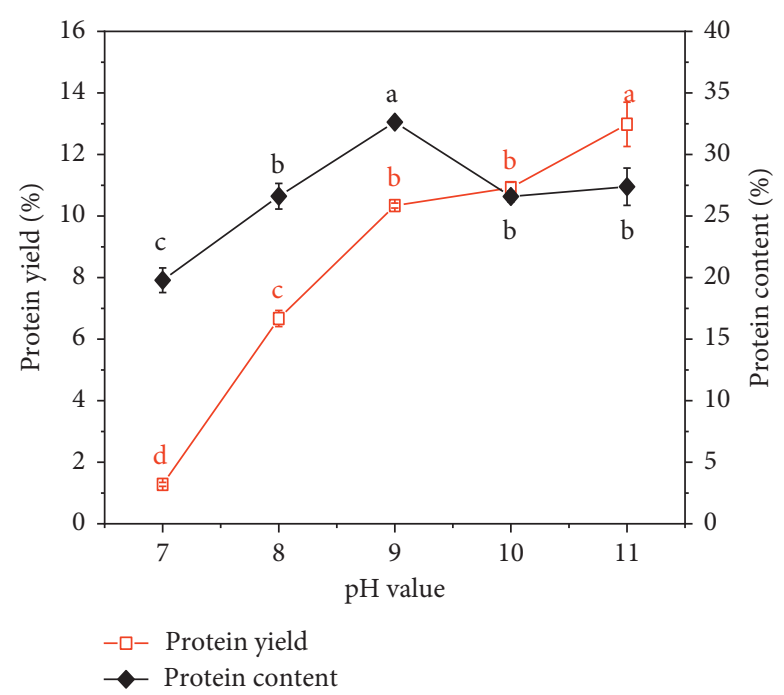

(b)

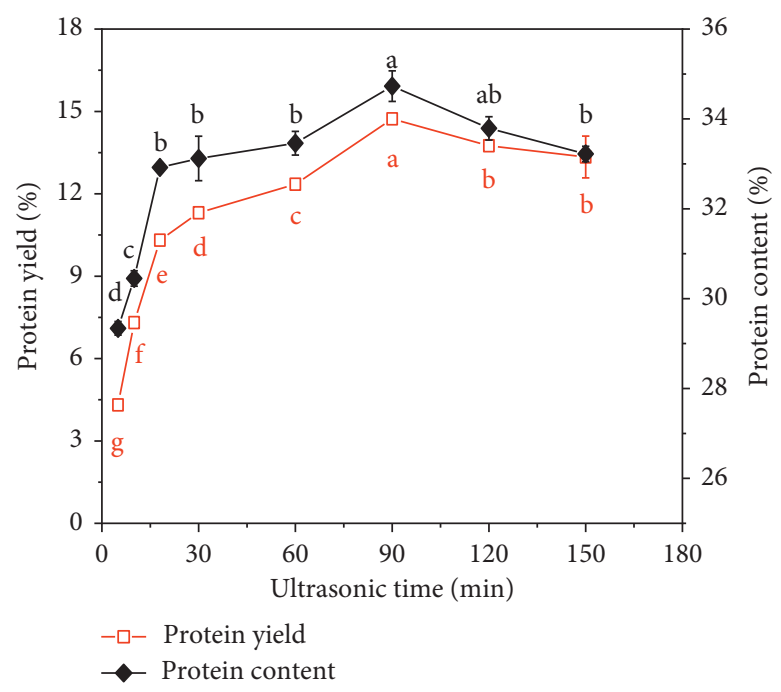

(d)

FIGURE 3: Effects of solid-liquid ratio (a), pH value (b), initial temperature (c), and ultrasonic time (d) on the yield and content of walnut protein. The different superscript letters of data under the same line indicate that they are significantly different $(p<0.05)$.

protein, and the protein-water interactions of protein molecules and its solubility could be enhanced by increasing the alkaline conditions. Guo et al. [32] used $0.1 \mathrm{~mol} / \mathrm{L} \mathrm{NaOH}$ solution for rice protein extraction and achieved a higher protein yield (55\%). Lu et al. [33] used a $0.3 \mathrm{~mol} / \mathrm{L} \mathrm{NaOH}$ solution to extract protein from green tea and extracted a high content of protein (82\%). Ding et al. [34] used one method based on alkaline extraction for extracting protein from Camellia oleifera seed meal and obtained a high protein yield of $57.8 \%$ at a high alkaline condition.

The content of walnut protein significantly increased from $\mathrm{pH} 7$ to 9 and then significantly decreased after $\mathrm{pH} 9$ $(p<0.05)$. Jain and Anal [35] reported a similar trend that protein content initially increased as $\mathrm{pH}$ increased. When the $\mathrm{pH}$ value was greater than 8 , it was observed that the content followed a decreasing trend. The decreased protein content as $\mathrm{pH}$ increased may be due to a decrease in the proportion of the dissolved protein in the lye soluble substance as the $\mathrm{pH}$ continued to rise. It was reported that higher alkaline extraction can increase the brownish appearance and unpleasant bitterness [36]. In addition, exposing the protein to extreme alkaline conditions might cause the degradation of proteins and potential toxicity, such as the formation of lysinoalanine, resulting in the loss of nutritional value [37]. On the contrary, SFU-assisted alkali extraction can reduce the use of alkali and the production of harmful substances. By considering the protein content, protein yield, and product quality, $\mathrm{pH} 9$ was more appropriate and applied to the following optimization.

3.1.7. Initial Temperature. The effects of initial temperature $\left(15,25,35,45\right.$, and $\left.55^{\circ} \mathrm{C}\right)$ on the yield and content of walnut protein were studied, and the data is shown in Figure 3(c). 
From the view of protein yield, it was in a slow rise phase from $15^{\circ} \mathrm{C}$ to $45^{\circ} \mathrm{C}$ and then significantly increased from $45^{\circ} \mathrm{C}$ to $55^{\circ} \mathrm{C}(p<0.05)$. This was because the temperature had a positive effect on the dissolution and extraction of protein. Shewry and Miflin [38] found a similar phenomenon of the significant influence of temperature in the extraction of crude protein from Termitomyces albuminosus. With the increase in temperature, the ultrasonic cavitation effect also increased due to the decreasing of cavitation threshold caused by increased temperature except for the thermal effect. Because of the combination of temperature and ultrasound, the protein yield was increased significantly. However, the protein content decreased significantly with the increase in temperature $(p<0.05)$. This may be due to the decreasing proportion of the dissolved protein in the lye soluble substance. Moreover, it was reported that high temperature and high ultrasonic cavitation could change the structure of the protein and cause protein aggregation and degradation and thus affected the protein content. Consequently, the high ultrasonic temperature was not always recommended. Therefore, by full consideration of the yield and content, as well as the energy consumption of temperature, $25^{\circ} \mathrm{C}$ was chosen as the appropriate initial temperature and applied to the following optimization.

3.1.8. Ultrasonic Time. The effects of ultrasonic time $(5,10$, $18,30,60,90,120$, and $150 \mathrm{~min}$ ) on the yield and content of walnut protein were studied. The results are plotted in Figure $3(\mathrm{~d})$. With the prolongation of the ultrasonic time, the protein yield rapidly increased within $5 \sim 18 \mathrm{~min}$, then slowly increased $(18 \sim 90 \mathrm{~min})$, and finally decreased (90 150 $\mathrm{min})$. The protein yield reached the maximum $(14.7 \%)$ at the ultrasonic time of $90 \mathrm{~min}$. With the increased ultrasonic time, the cavitation effect correspondingly increased [39], which promoted the dissolution of protein in solution and eased the extraction. This led to an increase in protein yield. The decline of protein yield at later extraction time may be due to the stronger thermal effect produced by ultrasonic treatment for a longer ultrasonic time. With the temperature further increased, the decomposition or aggregation of protein occurred. Xu et al. [31] found a similar trend of soluble leaf protein yield that initially increased with ultrasonic time and then decreased. Similarly, Sun et al. [40] studied that the yield of polysaccharides from the fruit of Camptotheca acuminata was increased steadily and then decreased with the extended extraction time. The changing trend of protein content was the same as that of yield. The protein content reached the maximum (34.7\%) at the ultrasonic time of $90 \mathrm{~min}$. After the ultrasonic time of $90 \mathrm{~min}$, the protein content slowly decreased, which was due to a relative decreasing proportion of the dissolved protein in the lye soluble substance caused by the decomposition of proteins. Therefore, the ultrasonic time of $90 \mathrm{~min}$ was chosen as the appropriate treatment time.

Through the screening of processing parameters, the SFU extraction condition of walnut protein was optimized. Under the solid-liquid ratio of $1: 12, \mathrm{pH}$ value of 9 , the initial temperature of $25^{\circ} \mathrm{C}$, ultrasonic frequency of $28 \mathrm{kHz}$, sweep frequency amplitude of $1.5 \mathrm{kHz}$, sweep frequency cycle of $100 \mathrm{~ms}$, the duty ratio of $77 \%$, and ultrasonic time of $90 \mathrm{~min}$, the walnut protein yield (14.7\%) and the walnut protein content $(34.7 \%)$ were increased by $34.9 \%$ and $9.8 \%$, compared to conventional alkali extraction (10.9\% and $31.6 \%)$. Therefore, SFU treatment could be used as an effective auxiliary technology in the alkali extraction of heat-sensitivity walnut protein.

\subsection{Structural Analysis}

3.2.1. FT-IR Analysis. The functional groups of walnut proteins extracted with and without ultrasound were analyzed by FT-IR (Figure 4). It was reported that the peak at $1700 \sim 1600 \mathrm{~cm}^{-1}$ corresponds to amide I vibration, the peak at $1600 \sim 1500 \mathrm{~cm}^{-1}$ corresponds to amide II vibration, and the peak at $1046 \sim 1047 \mathrm{~cm}^{-1}$ corresponds to stretching vibration of C-N covalent bond [41]. The results showed that single alkali and SFU extracted proteins both had absorption peaks at 3419.8 and $3377.4 \mathrm{~cm}^{-1}$, which corresponded to the $\mathrm{O}-\mathrm{H}$ stretching vibration. Compared to the protein prepared by the single alkali extraction, the absorption peak of SFUassisted extracted protein showed an obvious shift to lower wavenumber $\left(3377.4 \mathrm{~cm}^{-1}\right)$. When the intermolecular or intramolecular hydrogen bonding is strengthened, the absorption peak will move to a high wavenumber [42]. This indicated that the intermolecular/intramolecular hydrogen bond force was decreased by ultrasonic treatment compared to the single alkali extraction method. Qu et al. [43] found the same phenomenon in the ultrasonic treatment of rapeseed protein isolate-dextran conjugates. The weakening of hydrogen bond force indicated that the protein structure is looser and more soluble in an aqueous solution, which helps to improve the protein solubility. Compared to the protein prepared by the single alkali extraction, the absorption peaks at other wavenumbers did not change significantly $(p>0.05)$. Based on the present results, it was concluded that ultrasound changed the protein structure and decreased the intermolecular/intramolecular hydrogen bond binding of the protein. These structural changes were more conducive to the improvement of protein solubility, which could well explain the increases in the protein yield and protein content during SFU extraction (described in Section 3.1).

3.2.2. Fluorescence Analysis. The tertiary structures of walnut proteins extracted with and without ultrasound were analyzed by fluorescence (Figure 5). The residues of aromatic amino acids such as Trp, Tyr, and Phe can be excited by excitation light to produce fluorescence [44], which can be used to characterize the conformational changes of the tertiary structure of proteins. In this study, the maximum fluorescence emission (Figure 5(a)) and fluorescence excitation peaks (Figure 5(b)) of proteins extracted without and with ultrasound were located at $430 \sim 432 \mathrm{~nm}$ and $340 \sim 341 \mathrm{~nm}$, respectively. Despite no change in the peak position, the intensities of fluorescence emission and excitation of protein were significantly reduced by ultrasonic 


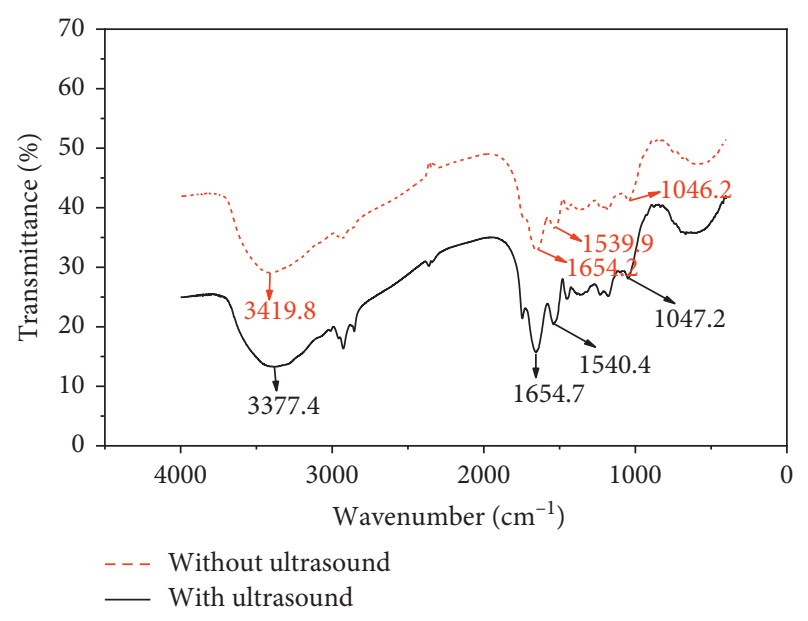

FIGURE 4: FT-IR spectra of walnut proteins extracted with and without ultrasound.

treatment. This phenomenon indicated that ultrasonic treatment changed the tertiary structure of protein and reduced the fluorescence intensity of the protein. The reason may be that ultrasonic cavitation reduced the amount of exposed chromophore, thus resulting in the decrease of protein fluorescence intensity [45]. Similarly, Zhang et al. [46] studied the influence of ultrasonic treatment on peanut protein isolate and found that sonication did not induce the shift of the wavelength of fluorescence emission peak but weakened the fluorescence intensity. In conclusion, the changes in fluorescence properties further proved that the SFU-assisted extraction altered the tertiary structure of proteins.

3.2.3. $C D$ Analysis. $C D$ is a rapid, simple, and accurate method for the detection of protein conformation. The CD spectrum can reflect the information of the secondary structure of proteins or polypeptide chains at the far UV range [47]. In the secondary structure, the $\alpha$-helix and $\beta$-sheet represent the order state of protein molecules, while the $\beta$-turn and random coil reflect the looseness of protein molecules. The results in Figure 6 showed that the proteins extracted without and with ultrasound had obvious negative absorption peaks at $210 \mathrm{~nm}$ and $209 \mathrm{~nm}$, respectively. According to the analysis of CDPro software, the secondary structure contents of walnut proteins were calculated, and the data is listed in Table 1 . It can be seen that the $\beta$-sheet contents of walnut proteins extracted with and without ultrasound both were high (53.0\% 54.4\%), indicating that the structure of the walnut protein was stable. In addition, the contents of $\alpha$-helix and random coil in the two samples changed significantly $(p>0.05)$, indicating that ultrasonic treatment had a significant effect on the secondary structure of the walnut protein. The content of $\alpha$-helix of protein extracted with ultrasound significantly increased by $42.2 \%$ and the content of random coil significantly decreased by $16.7 \%(p>0.05)$. The increase of $\alpha$-helix and the decrease of random coil indicated that the molecular structure of sonicated walnut protein became more order. Jiang et al.
[45] also observed small changes in the secondary structure of black soybean protein with ultrasound. Stathopulos et al. [48] reported an increase of $\beta$-sheet but a decrease in the protein aggregates following ultrasonic treatment. Vivian and Callis [49] found that there was an increase of $\alpha$-helix but a reduction in $\beta$-sheet with whey protein concentrate after ultrasonic treatment. The contradictory results probably attributed to the difference in protein types and test conditions. Based on the present results, in addition to affecting the tertiary structure of the walnut protein by fluorescence spectroscopic analysis (described in Section 3.2.2), the secondary structure of the walnut protein was significantly affected by ultrasonic treatment and became more order.

3.2.4. SEM Analysis. The microstructures of walnut proteins extracted with and without ultrasound were analyzed by SEM (Figure 7). A significant difference was observed for the microstructures of the walnut proteins extracted without and with ultrasound. Figure 7 (a) showed that the walnut protein without ultrasonic treatment was compact, presenting a relatively flat surface, while the microstructure of walnut protein with ultrasonic treatment shown in Figure 7(b) presented a loose structure, and the texture became porous and incompact. Qu et al. [43] also found that the surface structures of rapeseed protein isolate- (RPI-) dextran conjugates by ultrasonic treatment were more incompact and porous than RPI without ultrasound. Similarly, Zhao et al. [50] reported that the bulk density of the ultrasound-treated protein (loose structure) was smaller than that of the sample without ultrasound (compact structure), which helps to improve the solubility of the protein. It was concluded that ultrasonic treatment could improve the protein solubility by making the protein structure loose, which could well explain the increases in yield and content of protein during SFU-assisted extraction (described in Section 3.1).

3.3. Thermal Stability Analysis. Thermogravimetric analysis (TGA) can be used to analyze the pyrolysis rate of protein in different temperature environments [51]. Thermal stability properties were analyzed on walnut proteins extracted with and without ultrasound, and the results are shown in Figure 8. Regardless of the control or sonicated protein, the TGA (Figure 8(a)) and DTG curves (Figure 8(b)) showed that the two walnut proteins had a certain amount of weight loss in the first stage $\left(0 \sim 150^{\circ} \mathrm{C}\right)$. The weight loss at this phase mainly was related to free water evaporation in protein structure. The weight loss rates of the two groups at this stage were similar, and they reached the maximum at $79^{\circ} \mathrm{C}$. The second stage showed the rapid decomposition of protein $\left(150 \sim 369^{\circ} \mathrm{C}\right)$. At about $150^{\circ} \mathrm{C}$, the protein began to rapidly decompose, and most of the protein was rapidly decomposed by a high temperature at this stage [52]. The decomposition of protein was related to the noncovalent bonds including intermolecular and intramolecular hydrogen bonds, electrostatic interactions, and hydrophobic interactions. Except for noncovalent bonds, the covalent bonds in 


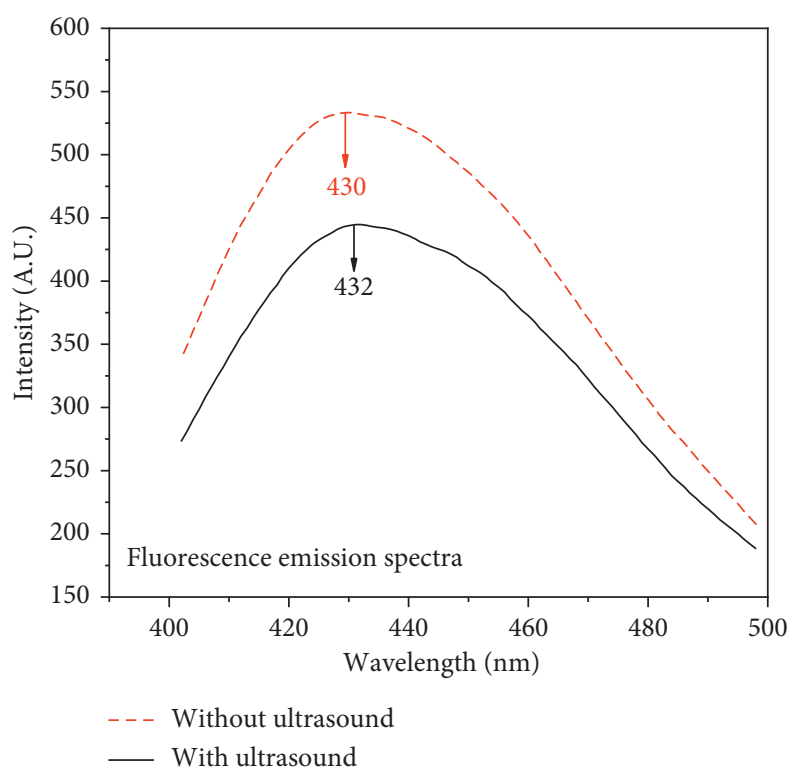

(a)

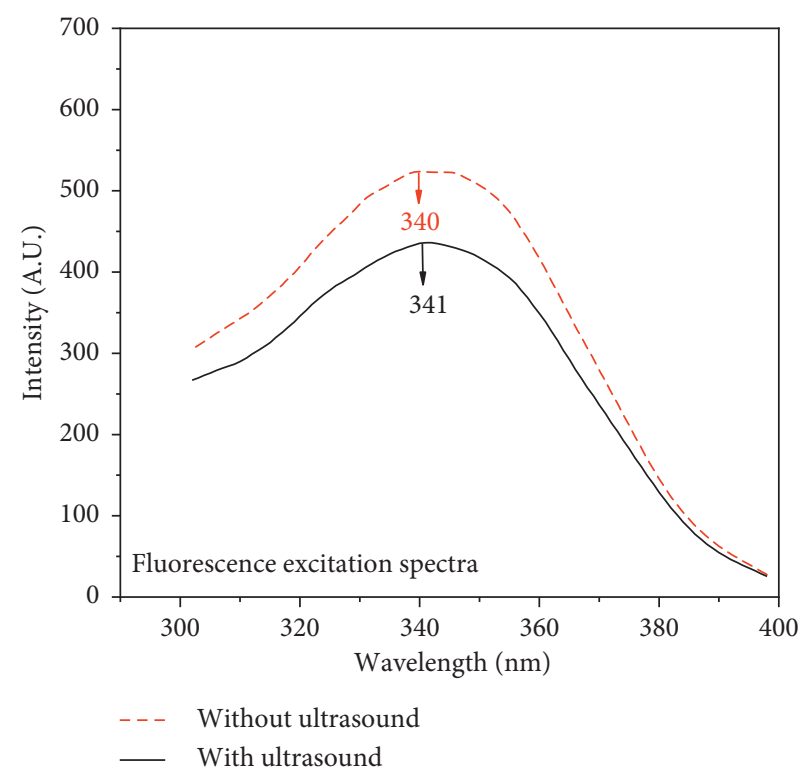

(b)

FIGURE 5: Fluorescence emission spectra (a) and excitation spectra (b) of walnut proteins extracted with and without ultrasound.

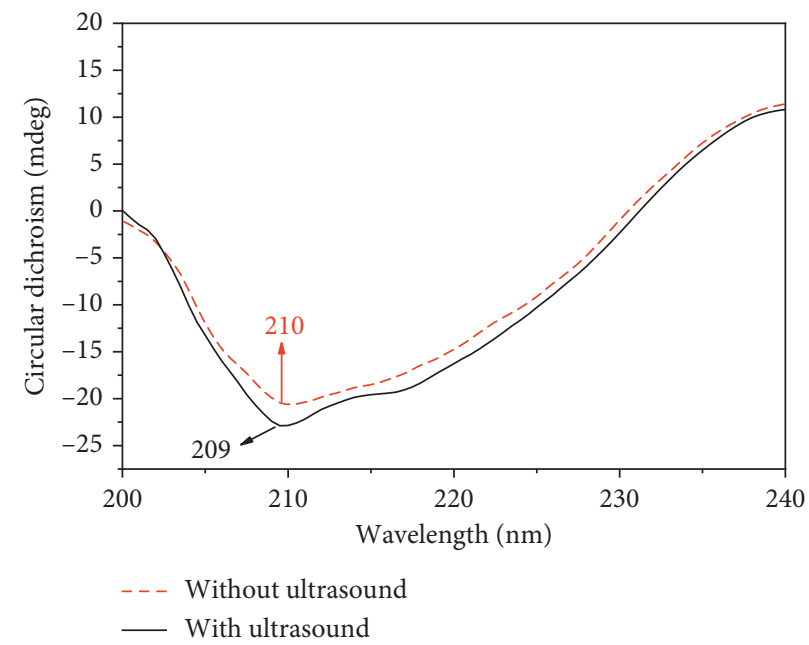

Figure 6: CD spectra of walnut proteins extracted with and without ultrasound.

TABLE 1: Secondary structures of walnut proteins extracted with and without ultrasound.

\begin{tabular}{lcccc}
\hline Sample & $\alpha$-helix $(\%)$ & $\beta$-sheet $(\%)$ & $\beta$-turn (\%) & Random coil (\%) \\
\hline Without ultrasound & $4.5 \pm 0.06^{\mathrm{b}}$ & $53.0 \pm 0.23^{\mathrm{a}}$ & $18.6 \pm 0.12^{\mathrm{a}}$ & $23.9 \pm 0.28^{\mathrm{a}}$ \\
With ultrasound & $6.4 \pm 0.04^{\mathrm{a}}(\uparrow 42.2)^{*}$ & $54.4 \pm 0.26^{\mathrm{a}}(\uparrow 2.6)$ & $19.3 \pm 0.14^{\mathrm{a}}(\uparrow 3.8)$ & $19.9 \pm 0.17^{\mathrm{b}}(\downarrow 16.7)$ \\
\hline
\end{tabular}

The different superscript letters of data under the same column indicate that they are significantly different $(p<0.05) .{ }^{*}$ The values in parenthesis are the change percentage points of secondary structure content in walnut protein with ultrasound compared to that without ultrasound.

the amino acid composition, such as $\mathrm{C}-\mathrm{N}, \mathrm{C}(\mathrm{O})-\mathrm{NH}$, and $\mathrm{C}(\mathrm{O})-\mathrm{NH}_{2}$, may be broken by a high temperature. The significant differences were observed in pyrolysis temperature between the walnut proteins extracted with ultrasound and without ultrasound. The maximum decomposition temperature of walnut protein extracted without ultrasound was $306^{\circ} \mathrm{C}$, and the maximum decomposition rate was $-0.369 \% /{ }^{\circ} \mathrm{C}$. However, the walnut protein extracted with ultrasound showed the lower decomposition rates at $319^{\circ} \mathrm{C}$ and $369^{\circ} \mathrm{C}$, corresponding to the decomposition rates of $-0.342 \% /{ }^{\circ} \mathrm{C}$ and $-0.336 \% /{ }^{\circ} \mathrm{C}$, respectively. This indicated that the SFU-assisted extraction obtained from walnut protein was more heat resistant. The third stage was the slower phase of mass loss in the range of $369 \sim 600^{\circ} \mathrm{C}$. The loss of weight at this stage was due to the oxidative decomposition of small molecules. Combined with the structural 


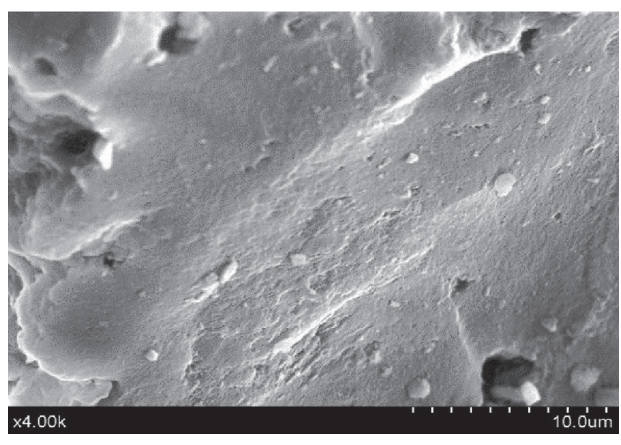

(a)

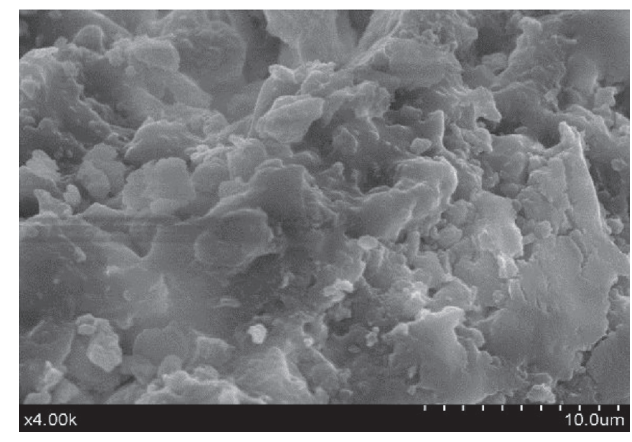

(b)

FIGURE 7: SEM photos of walnut proteins extracted without ultrasound (a) and with ultrasound (b).

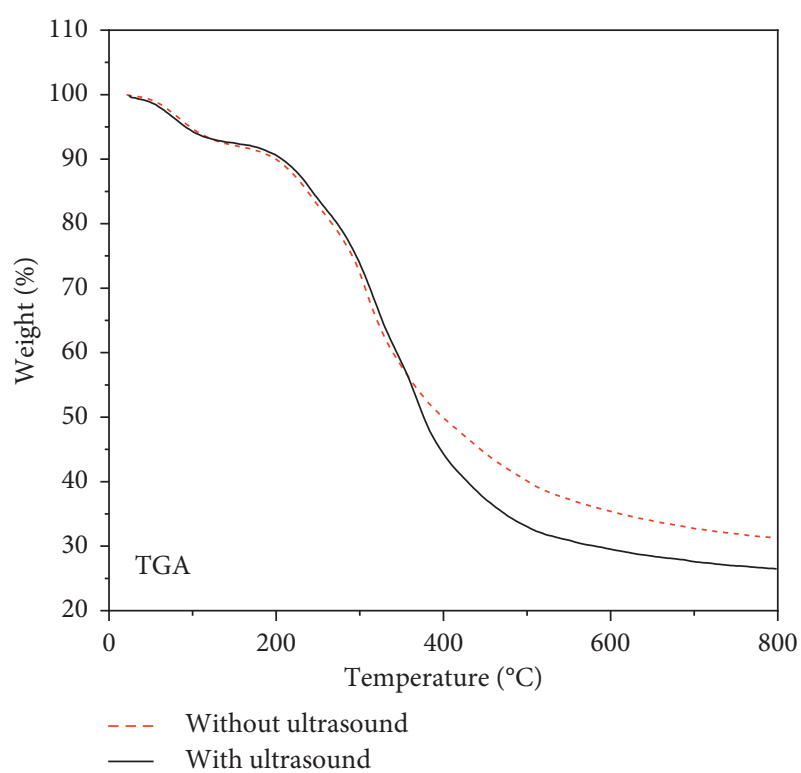

(a)

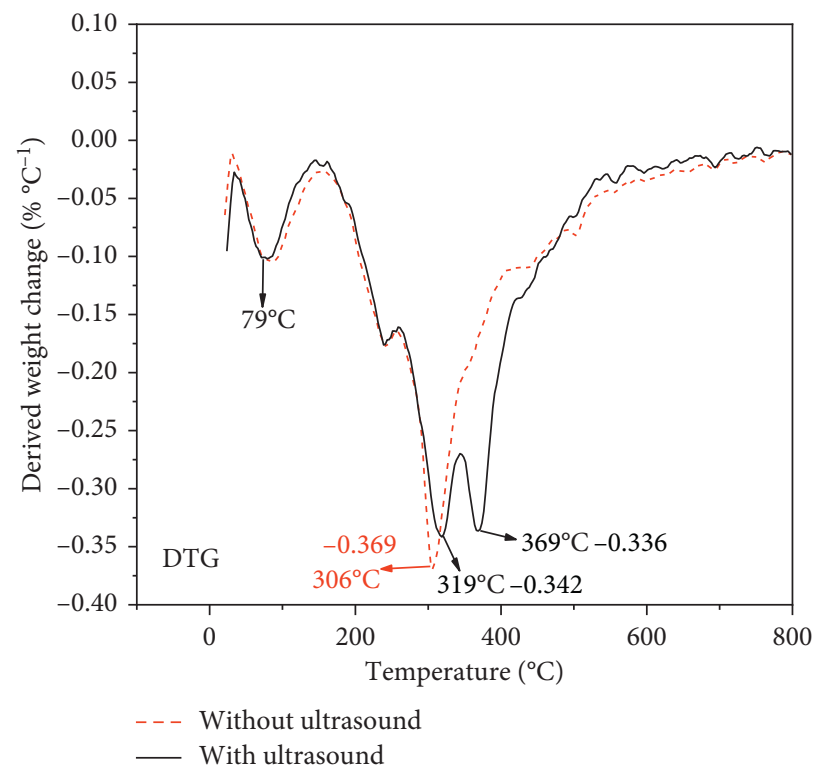

(b)

FIgURE 8: Thermal stability TGA (a) and DTG (b) of walnut proteins extracted with and without ultrasound.

changes (described in Section 3.2), it was concluded that the thermal stability of heat-sensitivity walnut protein was increased by ultrasonic treatment.

\section{Conclusions and Future Work}

This study indicated that sweep frequency ultrasound (SFU) could be used as an effective auxiliary technology of alkali extraction of heat-sensitivity walnut protein to enhance its yield and content. Compared to the conventional alkali extraction (10.9\% and 31.6\%), SFU-assisted extraction significantly increased the yield and content of protein by $34.9 \%$ and $9.8 \%$, respectively, at the optimum parameters as follows: solid-liquid ratio of $1: 12, \mathrm{pH}$ of 9 , the initial temperature of $25^{\circ} \mathrm{C}$, ultrasonic frequency of $28 \mathrm{kHz}$, sweep frequency amplitude of $1.5 \mathrm{kHz}$, sweep frequency cycle of $100 \mathrm{~ms}$, duty ratio of $77 \%$, and ultrasonic time of $90 \mathrm{~min}$. This improvement was due to the structural changes of the sonicated protein including the decreased intermolecular/ intramolecular hydrogen bond binding of protein, weakened fluorescence intensity, more order secondary structure, and more loosen microstructure, which could improve the thermoplastic and solubility of the heat-sensitivity walnut protein. Therefore, SFU treatment is an effective auxiliary technology in the alkali extraction of heat-sensitivity walnut protein. However, the biofunctions of the walnut meal protein were not investigated. Further studies on the functional characteristics of such high-valued protein will help to build the extraction criteria of the walnut meal. It will also facilitate the application of ultrasound in bioactive ingredients extraction from industrial and agricultural byproducts.

\section{Data Availability}

The data supporting the results of this study are available within the paper or are available from the corresponding author upon reasonable request.

\section{Conflicts of Interest}

The authors declare that they have no conflicts of interest. 


\section{Acknowledgments}

The authors wish to extend their appreciation to the National Natural Science Foundation-China (31872892), National Key Research and Development Program of ChinaIntergovernmental Key Program for International Science and Technology Innovation Cooperation (2017YFE0105300), and "Six Talents Peak" High-Level Talent Program of Jiangsu Province (NY-010).

\section{References}

[1] H. C. Huang, Z. F. Jiang, and H. J. Zhu, "The methods of protein conformation predicted by UV-circular dichroism," Chemistry, vol. 70, no. 7, pp. 501-506, 2007.

[2] X. N. Wang, L. J. Lin, and F. J. Wang, "Optimization of fermentation conditions for preparing walnut soy sauce," Science and Technology of Food Industry, vol. 35, no. 5, pp. 209-212, 2014.

[3] H. J. Xu, Y. B. Hao, J. X. Qi, G. S. Fan, and K. J. Wang, "Study on antioxidant activity and antihypertensive activity of enzymatic hydrolysis products of walnut protein," Innovational Edition of Farm Products Processing, vol. 10, pp. 38-42, 2009.

[4] X.-Y. Mao and Y.-F. Hua, "Chemical composition, molecular weight distribution, secondary structure and effect of $\mathrm{NaCl}$ on functional properties of walnut (Juglans regia L) protein isolates and concentrates," Journal of Food Science and Technology, vol. 51, no. 8, pp. 1473-1482, 2014.

[5] K. W. C. Szemilao and S. K. Sathe, "Walnuts (Juglans regia L): proximate composition, protein solubility, protein amino acid composition and protein in vitro digestibility," Journal of the Science of Food \& Agriculture, vol. 80, pp. 1393-1401, 2000.

[6] R. Geng, W. Lu, and M. K. Wang, "The research status of walnut quality and process technology," Farm Products Processing, vol. 5, pp. 69-72, 2015.

[7] L. Jiang, H. D. Xu, Y. J. He, and Z. F. Hu, "Study on extraction of walnut cake protein and its functional," Food Science and Technology, vol. 4, pp. 237-240, 2007.

[8] S. Cofrades, A. Serrano, J. Ayo, J. Carballo, and F. JiménezColmenero, "Characteristics of meat batters with added native and preheated defatted walnut," Food Chemistry, vol. 107, no. 4, pp. 1506-1514, 2008.

[9] R. Toews and N. Wang, "Physicochemical and functional properties of protein concentrates from pulses," Food Research International, vol. 52, no. 2, pp. 445-451, 2013.

[10] Q. Zhao, C. Selomulya, H. Xiong et al., "Comparison of functional and structural properties of native and industrial process-modified proteins from long-grain indica rice," Journal of Cereal Science, vol. 56, no. 3, pp. 568-575, 2012.

[11] F. Y. Fan, Y. P. Wang, Y. J. Ma, Y. C. Xu, and Y. J. Yang, "Study on protein extraction process from walnut," Academic Periodical of Farm Products Processing, vol. 5, pp. 13-15+19, 2010.

[12] N. Chen, H. Yang, Y. Sun, J. Niu, and S. Liu, "Purification and identification of antioxidant peptides from walnut (Juglans regia L.) protein hydrolysates," Peptides, vol. 38, no. 2, pp. 344-349, 2012.

[13] R. Velmurugan and K. Muthukumar, "Ultrasound-assisted alkaline pretreatment of sugarcane bagasse for fermentable sugar production: optimization through response surface methodology," Bioresource Technology, vol. 112, pp. 293-299, 2012.

[14] P. B. Subhedar and P. R. Gogate, "Alkaline and ultrasound assisted alkaline pretreatment for intensification of delignification process from sustainable raw-material," Ultrasonics Sonochemistry, vol. 21, no. 1, pp. 216-225, 2014.

[15] P. Filson and B. Dawsonandoh, "Sono-chemical preparation of cellulose nanocrystals from lignocellulose derived materials," Bioresource Technology, vol. 100, no. 7, pp. 2259-2264, 2009.

[16] A. Szydłowska-Czerniak, A. Tułodziecka, G. Karlovits, and E. Szlyk, "Optimisation of ultrasound-assisted extraction of natural antioxidants from mustard seed cultivars," Journal of the Science of Food \& Agriculture, vol. 95, no. 7, pp. 1445-1453, 2015.

[17] W. Qu, H. Ma, J. Jia, R. He, L. Luo, and Z. Pan, "Enzymolysis kinetics and activities of ace inhibitory peptides from wheat germ protein prepared with SFP ultrasound-assisted processing," Ultrasonics Sonochemistry, vol. 19, no. 5, pp. 1021-1026, 2012.

[18] Y. Y. Wang, J. K. Yan, Y. H. Ding, M. T. Rashid, and H. L. Ma, "Effect of sweep frequency ultrasound and fixed frequency ultrasound thawing on gelling properties of myofibrillar protein from quick-frozen small yellow croaker and its possible mechanisms," LWT-Food Science and Technology, vol. 150, p. 111922, 2021.

[19] J. Wang, H. Ma, Z. Pan, and W. Qu, "Sonochemical effect of flat sweep frequency and pulsed ultrasound (FSFP) treatment on stability of phenolic acids in a model system," Ultrasonics Sonochemistry, vol. 39, pp. 707-715, 2017.

[20] H. Yang, W. Sheng, X. X. Zhang et al., "Effect of different ultrasonic treatment time on the physicochemical properties and structure of chicken blood plasma protein," Jiangsu Agricultural Sciences, vol. 47, no. 24, pp. 177-182, 2014.

[21] C. Yan and Z. Zhou, "Solubility and emulsifying properties of phosphorylated walnut protein isolate extracted by sodium trimetaphosphate," $L W T$, vol. 143, p. 111117, 2021.

[22] F. R. Hou, W. H. Ding, W. J. Qu et al., "Alkali solution extraction of rice residue protein isolates: influence of alkali concentration on protein functional, structural properties and lysinoalanine formation," Food Chemistry, vol. 218, pp. 207215, 2018.

[23] W. Qu, X. Zhang, X. Han, Z. Wang, R. He, and H. Ma, "Structure and functional characteristics of rapeseed protein isolate-dextran conjugates," Food Hydrocolloids, vol. 82, pp. 329-337, 2018.

[24] L. Zhang, C. Zhou, B. Wang et al., "Study of ultrasonic cavitation during extraction of the peanut oil at varying frequencies," Ultrasonics Sonochemistry, vol. 37, pp. 106-113, 2017.

[25] P. Raviyan, Z. Zhang, and H. Feng, "Ultrasonication for tomato pectinmethylesterase inactivation: effect of cavitation intensity and temperature on inactivation," Journal of Food Engineering, vol. 70, no. 2, pp. 189-196, 2005.

[26] X. Ren, T. Hou, Q. Liang et al., "Effects of frequency ultrasound on the properties of zein-chitosan complex coacervation for resveratrol encapsulation," Food Chemistry, vol. 279, pp. 223-230, 2019.

[27] J.-K. Yan, Y.-Y. Wang, W.-Y. Qiu, Z.-B. Wang, and H. Ma, "Ultrasound synergized with three-phase partitioning for extraction and separation of Corbicula fluminea polysaccharides and possible relevant mechanisms," Ultrasonics Sonochemistry, vol. 40, pp. 128-134, 2018.

[28] Y. Lin, L. Lin, M. Cheng et al., "Effect of acoustic parameters on the cavitation behavior of SonoVue microbubbles induced by pulsed ultrasound," Ultrasonics Sonochemistry, vol. 35, pp. 176-184, 2017.

[29] S. L. Liu and B. Hu, "The study on the technology of preparation of walnut proteins," Food Research and Development, vol. 31, no. 10, pp. 107-110, 2010. 
[30] S. Q. Jing, "Optimization of the preparation of walnut protein with ultrasonic-assisted extraction method," Food Science and Technology, vol. 37, no. 2, pp. 251-255, 2012.

[31] Y. Xu, Y. Li, T. Bao, X. Zheng, W. Chen, and J. Wang, "A recyclable protein resource derived from cauliflower byproducts: potential biological activities of protein hydrolysates," Food Chemistry, vol. 221, pp. 114-122, 2017.

[32] R. R. Guo, S. Y. Pan, and K. X. Wang, "Comparing research on functionality of rice protein extracted by alkali and enzyme," Food Science, vol. 26, no. 3, pp. 173-177, 2005.

[33] C. Lu, S. K. Zhang, K. X. Zhu, B. Wang, and H. M. Zhou, "Extraction of tea protein using alkali extraction-acid precipitation method," Modern Food Science and Technology, vol. 27, no. 6, pp. 673-677, 2011.

[34] D. H. Ding, G. H. Peng, H. Xia, H. Wan, and D. P. He, "Orthogonal array design for extraction optimization of protein from camellia oleifera seed meal," Food Science, vol. 31, no. 8, pp. 102-105, 2010.

[35] S. Jain and A. K. Anal, "Optimization of extraction of functional protein hydrolysates from chicken egg shell membrane (ESM) by ultrasonic assisted extraction (UAE) and enzymatic hydrolysis," LWT-Food Science and Technology, vol. 69, pp. 295-302, 2016.

[36] H. Xi, Y. Liu, L. Guo, and R. Hu, "Effect of ultrasonic power on drying process and quality properties of far-infrared radiation drying on potato slices," Food Science and Biotechnology, vol. 29, no. 1, pp. 93-101, 2020.

[37] L. Xu and L. L. Diosady, "Removal of phenolic compounds in the production of high-quality canola protein isolates," Food Research International, vol. 35, no. 1, pp. 23-30, 2002.

[38] P. R. Shewry and B. J. Miflin, "Seed storage proteins of economically important cereals," Advances in Cereal Science ¿Technology, vol. 7, pp. 1-83, 1985.

[39] J. Liu, L. X. Li, H. X. Wei et al., "Optimization of ultrasonicassisted extraction process of crude protein from Termitomyces albuminosus and its antioxidant activity," Science and Technology of Food Industry, vol. 40, no. 10, pp. 221-226, 2019.

[40] H. Sun, C. Li, Y. Ni et al., "Ultrasonic/microwave-assisted extraction of polysaccharides from Camptotheca acuminata fruits and its antitumor activity," Carbohydrate Polymers, vol. 206, pp. 557-564, 2019.

[41] Q. H. Zhang, X. Q. Huang, M. Y. Li, Y. X. Liu, and J. W. Zhang, "Study on secondary structure of meat protein by FTIR," Food and Fermentation Industries, vol. 41, no. 10, pp. 247-251, 2015.

[42] Y. Mine, "Effect of dry heat and mild alkaline treatment on functional properties of egg white proteins," Journal of Agricultural and Food Chemistry, vol. 45, no. 8, pp. 2924-2928, 1997.

[43] W. Qu, X. Zhang, W. Chen, Z. Wang, R. He, and H. Ma, "Effects of ultrasonic and graft treatments on grafting degree, structure, functionality, and digestibility of rapeseed protein isolate-dextran conjugates," Ultrasonics Sonochemistry, vol. 42, pp. 250-259, 2018.

[44] Y. X. Yin, B. Q. Xiang, and L. Tong, "The application of studying fluorescence spectroscopy on protein," Experimental Technology and Management, vol. 27, no. 2, pp. 33-40, 2010.

[45] L. Jiang, J. Wang, Y. Li et al., "Effects of ultrasound on the structure and physical properties of black bean protein isolates," Food Research International, vol. 62, pp. 595-601, 2014.

[46] Q.-T. Zhang, Z.-C. Tu, H. Xiao et al., "Influence of ultrasonic treatment on the structure and emulsifying properties of peanut protein isolate," Food and Bioproducts Processing, vol. 92, no. 1, pp. 30-37, 2014.
[47] X. C. Shen, H. Liang, X. W. He, and X. S. Wang, "Recent trends and spectroscopic methods for analysis of the protein conformation with circular dichroism," Chinese Journal of Analytical Chemistry, vol. 32, no. 3, pp. 388-394, 2004.

[48] P. B. Stathopulos, G. A. Scholz, Y. M. Hwang, J. Rumfeldt, and J. R. Lepock, "Sonication of proteins causes formation of aggregates that resemble amyloid," Protein Science, vol. 13, no. 11 , pp. 3017-3027, 2010.

[49] J. T. Vivian and P. R. Callis, "Mechanisms of tryptophan fluorescence shifts in proteins," Biophysical Journal, vol. 80, no. 5, pp. 2093-2109, 2001.

[50] R. Z. Zhao, J. Jiang, J. W. Lin, and Y. F. Liu, "Influence of roast processing on secondary structure, surface hydrophobicity and emulsifying properties of walnut protein," Science and Technology of Food Industry, vol. 37, no. 16, pp. 157-166, 2016.

[51] Y. Feng, B. Xu, A. E. A. Yagoub et al., "Role of drying techniques on physical, rehydration, flavor, bioactive compounds and antioxidant characteristics of garlic," Food Chemistry, vol. 343, p. 128404, 2021.

[52] P. Liu, Z. Ji, and F. S. Chen, "Microwave and ultrasoundassisted conventional alkali extraction of wheat bran protein," Journal of Qi Lu University of Technology, vol. 32, no. 1, pp. 6-12, 2018. 